\title{
Employer-Sponsored Training And Job Retention Of Mid-Career Employees
}

\author{
Sumati Srinivas, Radford University, USA
}

\begin{abstract}
Recent research on training has been focused on explaining the empirical finding that many employers often sponsor training that employees could potentially use in other firms (i.e., general training). This paper studies employer-sponsored general training for mid-career employees, who form an important but neglected subset of workers in the training context. The results indicate that college-educated workers in specialized professional occupations are the most common recipients of employer-sponsored general training. Analysis of employee retention rates indicates that midcareer workers that receive employer sponsored training are less likely to voluntarily quit their jobs post-training. Cross training and computer training have the most significant positive effects on employee job retention while only a regular training program to upgrade skills appears to produce positive employee job retention effects.
\end{abstract}

Keywords: General Training, Job Mobility, Labor Economics and Mid-career Workers.

\section{INTRODUCTION}

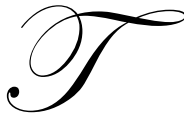

raining on the job has become a major source of skill accumulation for workers in the last two decades due to the rapid pace of technological change. Studies by Bishop (1994) and Bartel and Lichtenburg (1987), among others, establish that a well-trained workforce provides returns to employers in the form of higher productivity and better adaptability to technological change. Hence, there is a strong incentive for employers to sponsor training for their workforce. However, employers also need to reckon with the possibility that workers may quit before employers can fully realize the benefits of the training that was provided.

For nearly three decades since Becker (1964) classified training as general training (training that builds skills transferable to other firms) or specific training (training that builds firm-specific skills), researchers have assumed that employers would be more willing to sponsor specific training as opposed to general training that could be used elsewhere. However, many recent empirical studies have failed to provide any evidence for this notion. Instead, empirical research has consistently found that most employer-sponsored training does, in fact, provide employees with skills that are transferable to other employers (i.e., that most employer-sponsored training should be classified as general training). Studies by Barron, Berger and Black (1999), Loewenstein and Spletzer (1999), Booth and Bryan (2002) find, that most or all the training that is sponsored by employers result in workers acquiring general skills that can be used at other firms.

Such recent findings have sparked a renewed interest in the following question: do workers who acquire transferable skills from employer-sponsored training continue working in the same job or do they seek better returns for their newly acquired skills from other employers? While this question has been explored in many recent studies, most of this research (possibly due to the nature of the survey data available) has focused on younger workers or a cross-section of workers.

In doing this, workers who are in the middle of their careers - a subset of workers who enjoy a considerable benefit from training - have been overlooked. It is well-understood that the type of training undergone by young workers is substantially different from the re-training of mid-career workers. De Grip and Van Loo (2002) detail the various ways in which a worker's skill may degrade over the course of a career, necessitating remedial on-the-job 
training is often essential to maintaining worker productivity. In this context, it could be reasonably expected that the nature of training mid-career employees receive would take fundamentally different forms than training for the labor force at large. Also, workers tend to be highly mobile between jobs early in their careers; Topel and Ward (1992), for example, show that a typical worker holds seven different jobs during the first 10 years of his/her career, with the rate of job mobility subsequently declining significantly. Hence, employers may be more willing to sponsor general training for such workers, believing that they would be more likely to experience the rewards of this training due to the decreased job mobility at this stage of the worker's career.

Hence, it is interesting to investigate that the nature and effects of general training for mid-career employees, an area of research that has been neglected in the literature on general training. This paper explores this research problem and seeks, in particular, to answer the following questions:

1. What type of mid-career employees are most likely to get employer provided training?

2. What, if any, relationship exists between the provision of employer-sponsored training and post-training voluntary quit rates of mid-career employees?

3. Does the type of training received influence the employee retention rates among mid-career employees?

4. Does training of mid-career employees mostly take the form of retraining those with deteriorating skills or expanding the skill-set of the most productive employees?

Answering these questions, besides filling a crucial gap in the general training literature, have wide-ranging practical implications. This analysis would help employers decide on the kind of training for mid-career employees that will provide the best returns by maximizing employee retention. It would also provide new insights into the practice of employer-sponsored general training among mid-career employees in the United States, by determining the types of employees who are more likely to receive such training, in terms of demographic and other characteristics. Finally, the research questions investigated here are interesting from a public policy perspective, since determining the need and effectiveness of re-training mid-career employees has important implications for maintenance of the skill levels of the labor force in general in the face of technological change.

\section{RESEARCH BACKGROUND}

\section{Why Do Employers Sponsor General Training?}

One of the most interesting questions explored by recent research into training is: why do employers pay for training workers on skills that could be potentially used in working for other firms (so-called "general training")? The most commonly accepted explanation of this phenomenon is provided by Acemoglu and Pischke (1999). In this model, employers pay for general training in cases where the increased productivity of their employees as a result of the training is not matched by a proportional increase in their wages after training (i.e., their wages are compressed with respect to productivity). This compression may be due to various sources of labor market frictions - in the most obvious example, unions may fix the salary range, and hence workers may not be able to get increased wages proportional to their increased skills after training.

Many studies have attempted to find empirical evidence for this model, with mixed results. For example, Booth and Zoega (2004) using British data find evidence of wage compression in workers who receive firmsponsored training, but Peraita (2001) does not discover an increased incidence of training in a study of workers who have highly compressed wage structures.

A survey of recent research on labor market frictions suggests that there may be other factors at work besides wage compression that encourages employers to pay for general training. Bhaskar et al (2002) provides an excellent summary imperfect competition in labor markets. Such imperfection competition results in employees incurring a cost when they change jobs, and in less job mobility than would be predicted by a model based on perfect competition. This, in turn, would encourage firms to sponsor general training as they would be more confident of being able to reap the benefits of training in the form of increased productivity. 


\section{General Training And Career Development}

With the wide range of differences in firm-sponsored general training only beginning to be recognized in the training literature, it is not surprising that little attention has been paid whether the career stage of a worker when training is provided has any relation to post-training job behavior. However, there is some evidence suggesting that the investment made in training, and hence the decision to sponsor employee training, differs depending on the career stage of the employee. Studies such as Bartel (1995) find that chances of receiving employer sponsored training increase greatly the longer an employee has been working for a firm. It is also easy to see that the labor market imperfections that hamper job mobility described above would matter far more in the case of mid-career workers than in the case of younger workers. Workers at the start of their careers have been shown to have much higher job mobility rates (Topel and Ward, 1992). Mid-career employees, having greater job tenures than younger workers, would also be affected more by the labor market imperfections that result in lesser mobility. For example, mid-career workers who have been retrained would be more likely to get better returns in their current job, due to their greater job tenure, than in the external job market.

Also, much of the research into general training tends to ignore the vast differences in the scope, methodology and context in which the training is provided. Training an employee in supervisory skills would, for example, be usually classified as general training. But, if such training is provided in the context of preparation for a promotion, it is more likely that the employee will continue in the job in order to receive the promotion. However, if the training is simply classified as "general training" (as it usually is in the literature), the loss of this context may result in a spurious finding of a positive correlation between general training and employee retention.

In this paper, both the nature of the general training of mid-career workers as well as the employee retention rates post-training are investigated. It is hypothesized here that factors other than wage compression, such as the type of training provided, play a large role in retaining mid-career employees after the training is completed. Hence, a particular point of interest is to find if there is a correlation between specific types of training for midcareer employees and increased retention rates.

\section{General Training And Job Mobility}

There is surprisingly little research done on the likelihood of employees quitting their jobs post-training, probably due to the lack of high-quality longitudinal data sets that would be required to do such analysis. The evidence that does exist in the literature paints a mixed picture. Lynch (1991), Gritz (1993), and Parent (1999) find that company training reduces the probability of job separations for young U.S. workers. In contrast, Krueger and Rouse (1998) who focus on personnel files from two large U.S. companies, and Veum (1997) who uses NLSY-data conclude that trainees are equally likely to quit than non-trainees.

This paper uses longitudinal data to determine whether workers who received training are still at their jobs two years after training. The two-year job retention rates have been used in many previous studies, such as Bernhardt et al. (1999) to model job stability. In this case, it provides a valuable insight into the determinants and likelihood of job retention for mid-career workers who receive employer-sponsored general training.

\section{DATA}

The analysis in this paper is carried out using data from the National Longitudinal Survey of Youth 1979 (referred to as the NLSY79). The NLSY79 is an ongoing survey of a nationally representative sample of 12,686 men and women. The respondents have been surveyed annually every year from 1979 to 1994, and once every two years from 1994 to 2006. During the years of the study presented here (2006 and 2008), the NLSY79 participants were aged between 41 and 49 , making them ideal for our purposes of studying the training patterns among mid-career employees.

The survey provides a rich set of information related to employment and training, including the occupational classification for each job held by the respondent at the time of the interview. Of the 6041 employed 
respondents in 2006, nearly 18 percent report receiving formal training of some kind. Each of these respondents are given an opportunity to report up to five different training programs they have received since the last survey, and provide many details regarding each training program.

Survey respondents are asked, for each training program they attend, the reason they were undergoing the training program. The five reasons given for general training, which are listed in Table 1, allow an analysis of whether the reasons why training was undertaken affects employee retention rates. Respondents are also asked to describe the skills that they obtained by the training program. The different skill sets learned are shown in Table 2. As can be seen from the analysis that follows, the richness of this training data is makes it very appropriate for the purposes of this study, since it makes it possible to take into account the heterogeneity of training offered by employers.

Table 1: Reasons for training

\begin{tabular}{|l|l|}
\hline \multicolumn{1}{|c|}{ Reason } & \multicolumn{1}{c|}{ Description } \\
\hline Promotion opportunity & Training was associated with promotion or job advancement opportunity \\
\hline New processes introduced & New methods or processes were introduced -- addtl training required to continue same job \\
\hline Regular training program & The training was part of a regular program to maintain and upgrade employee skills \\
\hline Necessary when starting job & The training was necessary when I began a job \\
\hline Necessary for certificate & The training was necessary for a license or a certificate \\
\hline
\end{tabular}

Table 2: Skills Learned by Training

\begin{tabular}{|l|l|}
\hline \multicolumn{1}{|c|}{ Skill } & \multicolumn{1}{c|}{ Description } \\
\hline Operating Equipment & Operation or repair of equipment \\
\hline Reading/Writing Skills & Improve reading, writing or math skills \\
\hline Computer Skills & Acquire or upgrade computer skills \\
\hline Managerial Skills & Learn to be a better supervisor/manager \\
\hline Skills Working as a Team & Upgrade skills working as a team or problem solving \\
\hline Cross Training Skills & Learn a wider range of jobs or cross-training \\
\hline
\end{tabular}

\section{ANALYSIS}

\section{Who Receives Employer-Sponsored Training?}

The summary statistics for the training dataset used for this analysis are shown in Table 3. From Table 3, it can be seen that about 13 percent of all mid-career workers received employer-sponsored general training. As befits a dataset of mid-career workers, the workers in this study show a median tenure of more than 5 years in their jobs. Also, forty percent of the workers reported that their highest level of education was a high school degree while about a third of them reported possessing a college degree or higher.

Table 3: Summary Statistics

\begin{tabular}{|l|c|c|c|c|c|}
\hline \multicolumn{1}{|c|}{ Variable } & Mean & Median & Minimum & Maximum & Std Dev \\
\hline Received General Training =1 & 0.13 & 0 & 0 & 1 & 0.3314723 \\
\hline Gender (Female =1) & 0.49 & 0 & 0 & 1 & 0.5000159 \\
\hline Race (Black =1) & 0.27 & 0 & 0 & 1 & 0.4422591 \\
\hline Age & 44.71 & 45 & 41 & 50 & 2.2372744 \\
\hline Job Tenure in weeks & 382.98 & 268 & 0 & 1797 & 352.4096149 \\
\hline Highest Degree (High School =1) & 0.40 & 0 & 0 & 1 & 0.4898233 \\
\hline Highest Degree (Some College =1) & 0.24 & 0 & 0 & 1 & 0.4284372 \\
\hline Highest Degree (College Degree =1) & 0.12 & 0 & 0 & 1 & 0.3280758 \\
\hline Highest Degree (Grad. Degree =1) & 0.11 & 0 & 0 & 1 & 0.3119827 \\
\hline
\end{tabular}


The analysis of employer sponsored training starts out with an overview of the differences between the kinds of mid-career workers who receive the training and those who do not. Figure 1 classifies employees by their occupation and identifies intra-occupational differences in the receipt of employer sponsored general training. The results reinforce previous research that such training is more prevalent among workers in highly-paid professional occupations, such as scientists and managerial occupations. In particular, a very high proportion of scientists and engineers (more than 1 in 4 ) report receiving employer sponsored general training within the last two years.

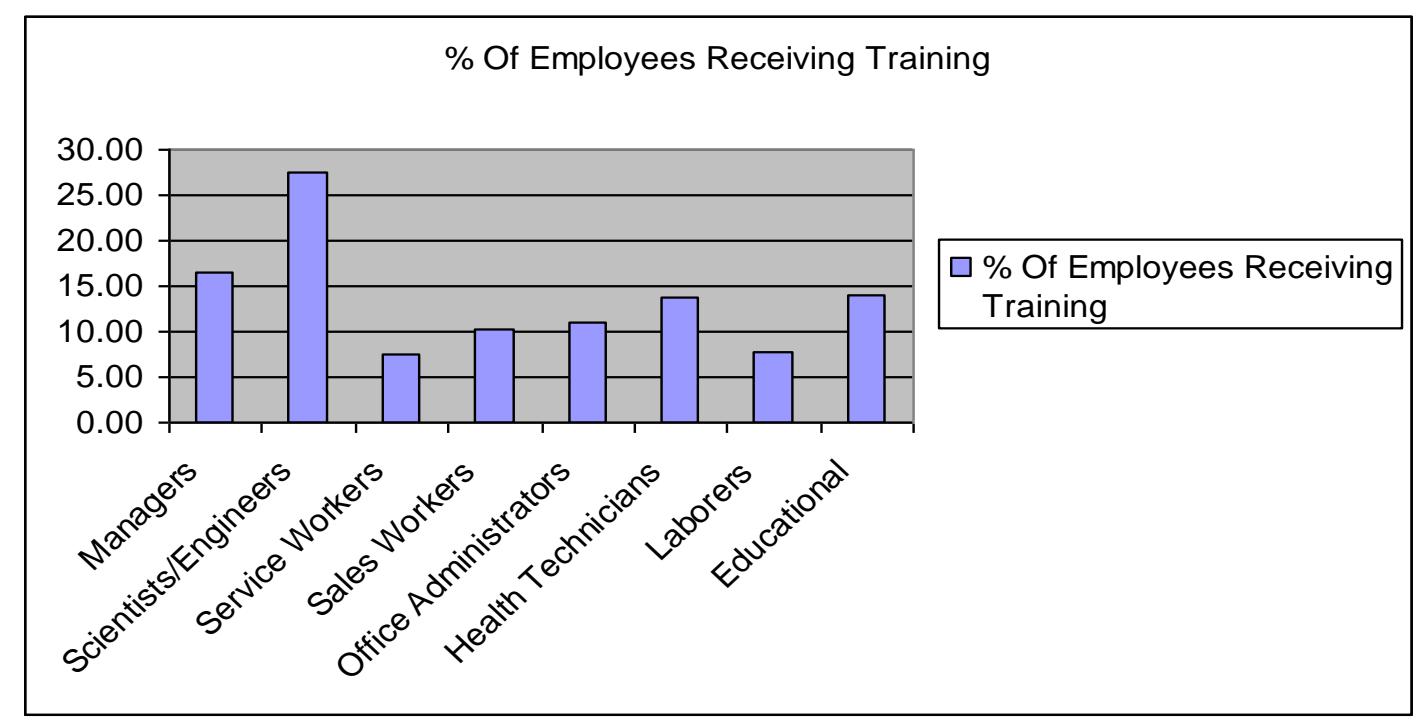

Figure 1: Percentage of Employees receiving General Training by Occupation

To obtain further insights into this occupational segregation of training, the relationship between receipt of general training and pay is directly tabulated and shown in Figure 2. Here we see that incidence of employersponsored training among mid-career employees peaks among those in the middle of the income distribution. Employees making between $\$ 50,000$ and $\$ 70,000$ are most likely to get trained, whereas the percentage of trainees drops off slightly for higher wage grades. Workers in the lower pay ranges are the worst off, with a noticeably smaller percentage of them receiving any employer-sponsored training.

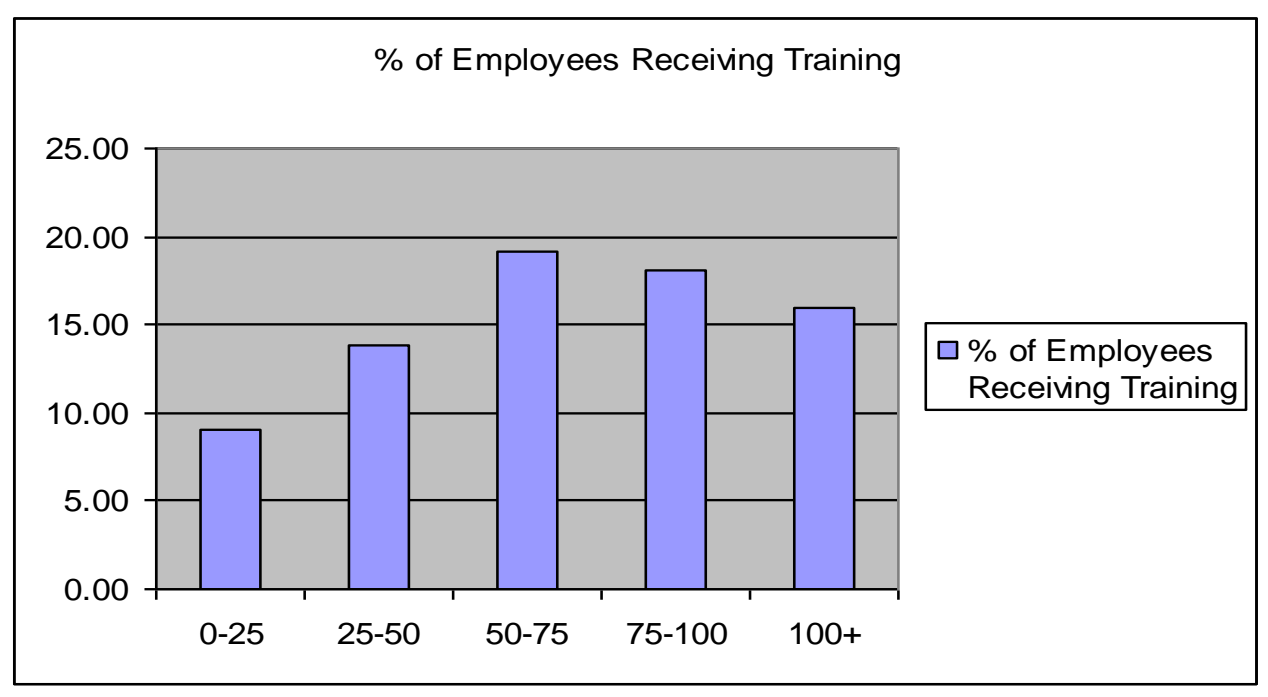

Figure 2: Percentage of Employees receiving training by annual wages 


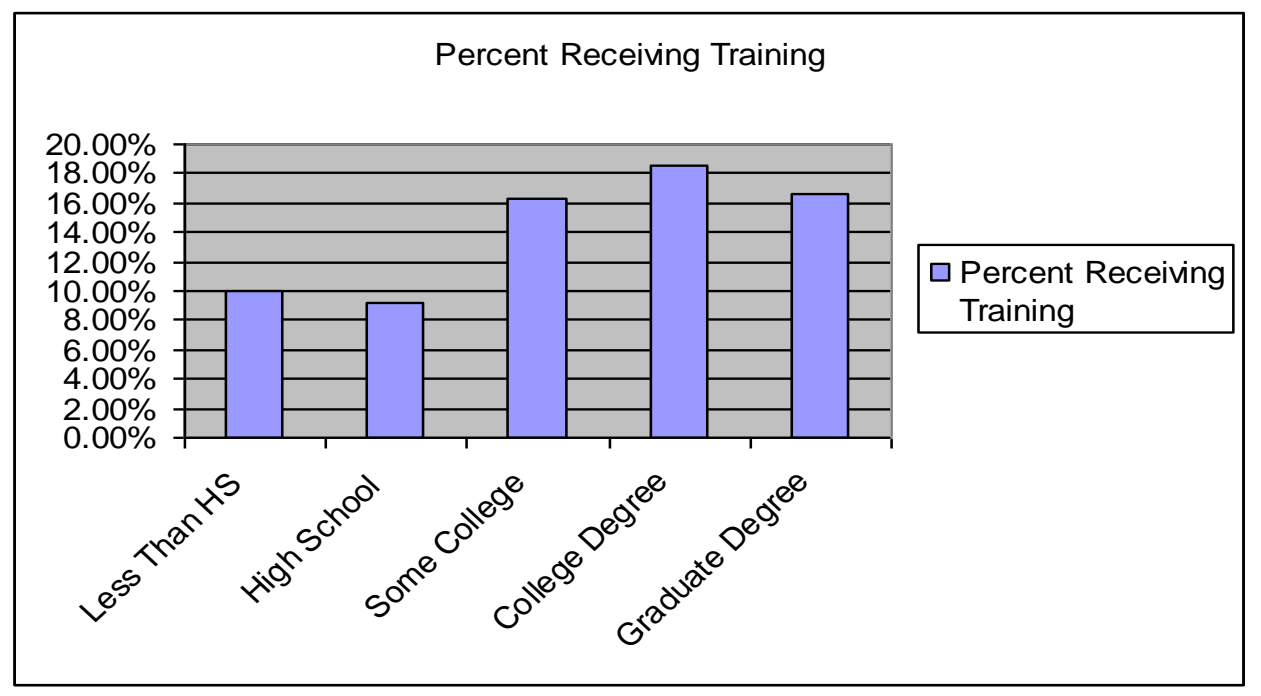

Figure 3: Percentage of employees receiving training by education

Next, the receipt of employer sponsored general training is tabulated against worker education levels. Figure 3 illustrates the education levels of employees plotted against the percentage of employees receiving employer-sponsored general training. The figure clearly illustrates the large difference between workers who have any level of college education and those who do not. As can be seen here, 16 to 18 percent workers with any level of college education receive training compared only 8-10 percent of workers with high school diplomas or less.

Finally, Table 4 shows the demographic and job related variables described above and their pair-wise correlations with the receipt of employer-sponsored general training. From this analysis, it can be clearly seen that, of the variables that are significantly correlated with the receipt of general training, the strongest positive correlation is with the possession of a college degree and the strongest negative correlation is with the possession of a high school diploma. The correlation with job tenure, though positive and significant, is still less than the effect of having any level of college education.

Table 4: Pearson Correlation Coefficients for Training and Demographic Variables

\begin{tabular}{|c|c|c|c|c|c|c|c|c|}
\hline & $\begin{array}{l}\text { Received } \\
\text { Training }\end{array}$ & $\begin{array}{c}\text { Job } \\
\text { Tenure }\end{array}$ & Female & Black & $\begin{array}{c}\text { High } \\
\text { School }\end{array}$ & $\begin{array}{c}\text { Some } \\
\text { College }\end{array}$ & $\begin{array}{l}\text { College } \\
\text { Degree }\end{array}$ & $\begin{array}{c}\text { Grad. } \\
\text { Degree }\end{array}$ \\
\hline Received Training & 1.000 & $0.051 * *$ & 0.007 & $-0.038 * *$ & $-0.083 * *$ & $0.063 * *$ & $0.068 * *$ & $0.043 * *$ \\
\hline Job Tenure & $0.051 * *$ & 1.000 & $-0.050 * *$ & $-0.053 * *$ & -0.002 & 0.002 & $0.028 * *$ & 0.016 \\
\hline Female & 0.007 & $-0.050 * *$ & $1.000 * *$ & $\mathbf{0 . 0 3 9} * *$ & $-0.052 * *$ & $0.082 * *$ & -0.005 & $0.033 * *$ \\
\hline Black & $-0.038 * *$ & $-0.053 * *$ & $0.039 * *$ & 1.000 & $0.043 * *$ & $0.057 * *$ & $-0.052 * *$ & $-0.072 * *$ \\
\hline High School & $-0.083 * *$ & -0.002 & $-0.052 * *$ & $0.043 * *$ & 1.000 & $-0.461 * *$ & $-0.305 * *$ & $-0.286 * *$ \\
\hline Some College & $0.063 * *$ & 0.002 & $0.082 * *$ & $0.057 * *$ & $-0.461 * *$ & 1.000 & $-0.211 * *$ & $-0.198 * *$ \\
\hline College Degree & $0.068 * *$ & $0.028 * *$ & -0.005 & $-0.052 * *$ & $-0.305 * *$ & $-0.211 * *$ & 1.000 & $-0.131 * *$ \\
\hline Grad. Degree & $0.043 * *$ & $0.016 * *$ & $0.033 * *$ & $-0.072 * *$ & $-0.286 * *$ & $-0.198 * *$ & $-0.131 * *$ & 1.000 \\
\hline
\end{tabular}

Note: $* *$ indicates significance at the 0.05 level.

Taken together, these descriptive statistics suggest the characteristics of mid-career employees who are most likely to receive employer-sponsored general training are as follows: they work in specialized professional occupations, have a college education, earn mid-to-high level wages and have established work histories for the employer who is sponsoring their training. This suggests that employers are more likely to sponsor general training 
for skilled, highly educated workers rather than to provide new skills to relatively unskilled workers with low levels of education.

\section{Training And Employee Retention}

I use a logistic regression to estimate the effects of training on the job retention of mid-career employees who receive training. Consider a worker $i$ who may or may not receive employer sponsored training at time $t$. I now estimate the following binary logit model:

$\operatorname{Pr}\left(Y_{i t+2}=1 \mid X_{i t}, T_{i t}\right)=f\left(X_{i t}, T_{i t}\right)$

where $\mathrm{Y}_{\mathrm{it}+2}$ is equal to 1 if the worker voluntarily has voluntarily quit the job held at time $t$ when observed at year $t+2, \mathrm{X}$ is a set of the worker's demographic and job-related variables and $\mathrm{T}_{\mathrm{it}}$ is a variable set to 1 if the worker received employer sponsored general training at time t. The demographic and job-related variables in $\mathrm{X}$ are the usual set of variables that are used to in models of job retention in the literature, including job tenure, race, sex and level of education, and occupational dummy variables to represent 5 different sectors that describe the worker's occupation. Note that since the interesting question is whether employer sponsored training encourages or discourages workers to continue working for the same employer, only voluntary quits are used in this analysis. Table 5 shows the results of the logit estimation.

From Table 5, it is clear that receiving general training significantly decreases the odds that the employee would have voluntarily quit their job within two years after receiving the training. Having a college education or a graduate degree also reduces the probability of voluntary quits, in line with the empirical literature that suggest that highly educated workers have more stable jobs. Also, workers in educational, sales and health technician occupations are shown to have significantly greater job instability.

Table 5: Odds Ratio Estimates of Determinants of Voluntary Quits

\begin{tabular}{|c|c|c|c|}
\hline \multirow[b]{2}{*}{ Received General Tr } & Point Estimate & \multicolumn{2}{|c|}{$\begin{array}{c}95 \% \text { Wald } \\
\text { Confidence Limits }\end{array}$} \\
\hline & $0.888 * *$ & 0.545 & 1.448 \\
\hline Gender $($ Female $=1)$ & $1.461 * *$ & 1.048 & 2.038 \\
\hline Job Tenure in weeks & $0.998 * *$ & 0.998 & 0.999 \\
\hline Race $($ Black $=1)$ & $1.339 *$ & 0.994 & 1.804 \\
\hline Highest Degree (High School =1) & 1.007 & 0.633 & 1.602 \\
\hline Highest Degree (Some College $=1$ ) & 0.823 & 0.487 & 1.390 \\
\hline Highest Degree (College Degree =1) & $0.557 *$ & 0.278 & 1.116 \\
\hline Highest Degree (Grad. Degree =1) & 0.521* & 0.247 & 1.097 \\
\hline Managerial Occupation $=1$ & 1.910 & 0.874 & 4.175 \\
\hline Science/Engineering Occupation $=1$ & 0.799 & 0.172 & 3.705 \\
\hline Educational Occupation $=1$ & $3.679 * *$ & 1.648 & 8.213 \\
\hline Sales Occupation $=1$ & $3.918 * *$ & 1.864 & 8.235 \\
\hline Health Technician Occupation $=1$ & $3.387 * *$ & 1.576 & 7.278 \\
\hline
\end{tabular}

Note: $*$ indicates the effect is significant at the 0.10 level. $* *$ indicates significance at the 0.05 level.

Having established that providing general training to mid-career employees has a significant positive effect on retaining those employees, I proceed to see if this effect varies depending on the type of skills that are imparted by the training. To do this, I replace the variable $T_{i t}$ in equation (1) with a set of dummy variables that are set to 1 for each of the different types of training that are listed in Table 2 . The results of the logit estimation with this new specification are shown in Table 6 (the demographic and occupational variables are not shown here although they were included in the estimation since their effects were similar to Table 5). 
As hypothesized earlier, the effect of training on employee retention varies widely depending on the skills imparted by the training. Employees who learn computer skills and employees who undergo cross training are significantly more likely to stay in their jobs, whereas employees who learn to operate new equipment are significantly (at the 0.10 level, but not the 0.05 level) likely to voluntarily quit their jobs when observed after two years. There is no significant effect of learning other skills through employer sponsored training on job retention.

Table 6: Odds Ratio Estimates of Determinants of Voluntary Quits by Skills Learned

\begin{tabular}{|l|c|c|c|}
\hline \multicolumn{1}{|c|}{ Skill Learned by Training } & \multirow{2}{*}{ Point Estimate } & \multicolumn{2}{c|}{ 95\% Wald } \\
\cline { 3 - 4 } & & \multicolumn{2}{c|}{ Confidence Limits } \\
\hline Operating New Equipment & $2.252^{*}$ & $\mathbf{1 . 1 3 9}$ & $\mathbf{4 . 4 5 3}$ \\
\hline Reading/Writing Skills & 1.154 & $\mathbf{0 . 5 0 3}$ & $\mathbf{2 . 6 4 9}$ \\
\hline Computer Skills & $\mathbf{0 . 5 7 4 *}$ & $\mathbf{0 . 2 6 7}$ & $\mathbf{1 . 2 3 7}$ \\
\hline Managerial Skills & $\mathbf{1 . 6 7 8}$ & $\mathbf{0 . 8 0 4}$ & $\mathbf{3 . 5 0 3}$ \\
\hline Skills Working as a Team & $\mathbf{1 . 0 5 2}$ & $\mathbf{0 . 5 3 1}$ & $\mathbf{2 . 0 8 3}$ \\
\hline Cross Training Skills & $\mathbf{0 . 6 5 0} * *$ & $\mathbf{0 . 2 9 8}$ & 1.417 \\
\hline
\end{tabular}

Note: * indicates the effect is significant at the 0.10 level. ** indicates significance at the 0.05 level.

Finally, I analyze whether the effect of training on employee retention varies because of the reason the training was initiated by the employer. To do this, I replace the variable $T_{i t}$ in equation (1) with a set of dummy variables that are set to 1 for each of the different reasons for training that are listed in Table 1 . . The results of the logit estimation with this new specification are shown in Table 7 (as before, the demographic and occupational variables are not shown here although they were included in the estimation since their effects were similar to Table $5)$.

These results are intriguing as they demonstrate that the employee retention effect are only significant when the training is a part a training program offered by the employer to regularly update the worker's skill. A smaller job retention effect is shown when the training is necessary because of new processes or methods that are introduced in the workplace. None of the other reasons given for employer sponsored general training have a significant effect on the odds for employee retention. However, since a regular training program is the most common reason for general training in our data, the positive effects on employee retention for this kind of program leads to a smaller positive effect for general training in general among in the overall population of mid-career workers used in this study.

Table 7: Odds Ratio Estimates of Determinants of Voluntary Quits by Skills Learned

\begin{tabular}{|c|c|c|c|}
\hline \multirow{2}{*}{$\begin{array}{l}\text { Reason for Training } \\
\text { Promotion onnortunity }\end{array}$} & Point Estimate & \multicolumn{2}{|c|}{$\begin{array}{c}95 \% \text { Wald } \\
\text { Confidence Limits } \\
\end{array}$} \\
\hline & 1.055 & 0.380 & 2.926 \\
\hline Regular training program & $0.671 * *$ & 0.271 & 1.659 \\
\hline New processes introduced & 0.992* & 0.516 & 1.908 \\
\hline Necessary when starting job & 1.143 & 0.350 & 3.733 \\
\hline Necessary for certificate & 1.448 & 0.660 & 3.176 \\
\hline
\end{tabular}

Note: * indicates the effect is significant at the 0.10 level. ** indicates significance at the 0.05 level.

\section{CONCLUSIONS}

The results described in this paper provide several interesting insights into the nature of employersponsored general training for mid-career employees and the effects of such training on employee retention. The investigation of demographic makeup of the workers who are trained shows that college educated workers in specialized professional occupations are more favored to receive employer-sponsored training programs. This suggests that among mid-career employees, unlike the population in general, employer sponsored training is much 
more likely to be intended to update and reinforce the skills of skilled workers, instead of training unskilled workers in new skills.

The logistic regression of voluntary quits unambiguously indicates that employer sponsored general training decreases the odds that mid-career employees quit post-training. This new finding adds a valuable new dimension to the research on the reasons for employers to sponsor general training, by providing a fresh insight into the behavior of this important subset of workers. The subsequent analyses of the type of training and the reasons for training highlights the complexity and heterogeneity of training that occurs in the workplace, and underscores the perils of treating all general training as homogenous, as is done in most of the literature on the subject.

The widely different impacts on employee retention of various training methods indicate many avenues for fruitful future research. The fact that computer training and cross training are the only types of training to significantly reduce the odds of voluntary quits post-training suggests that detailed studies of employer sponsored training of these kinds might provide interesting results. The effects of cross training, in particular, have been little studied in the economics literature so far and hence cross training of mid-career employees would appear to be a fertile area for future research.

The fact that a regular training program to upgrade employee skills is the only reason for training that has strong job retention significance among mid-career employees has important implications for employers. It is intriguing that even training programs that were initiated with specific promotion opportunities in mind do not significantly increase the odds of job retention whereas a regular training program does so. Further research into the links between the availability of such a regular training program and the job search decisions of employees would probably provide more valuable insights into the provision of training programs by employers for mid-career employees.

Sumati Srinivas is an assistant professor of economics in the College of Business and Economics at Radford University in Radford, VA. My primary area of research is labor economics with a particular focus on the changes occurring in the labor market in the last two decades due to the rapid spread of information technology. I have recently published articles in the International Journal of Social Economics and Research in Labor Economics.

\section{REFERENCES}

1. Acemoglu, D. and Pischke, J.-S. (1999). The structure of wages and investment in general training. Journal of Political Economy, 107, 539-72.

2. Barron, J.M., Berger, M.C. and Black, D.A., (1999). Do Workers Pay for On-the-Job Training? Journal of Human Resources, 34, 235-252.

3. Bashkar, V., Manning, Alan, and To, Ted (2002). Oligopsony and Monopsonistic Competition in Labor Markets. Journal of Economic Perspectives, vol. 16 (2), pp. 155-174.

4. Bishop, J.H. (1994) 'The impact of previous training on productivity and wages', in L. Lynch (ed.), Training and the Private Sector - International Comparisons, Chicago: University of Chicago Press.

5. Bartel, A. and F. Lichtenberg (1987). The Comparative Advantage of Educated Workers in Implementing New Technology. Review of Economics and Statistics, Vol. 69, No. 1 (Feb., 1987), pp. 1-11.

6. Bartel, A. (1995).Training, Wage Growth, and Job Performance: Evidence from a Company Database. Journal of Labor Economics, 13, 3, 401-425.

7. Bernhardt, Annette, Martina Morris, Mark S. Handcock, and Marc A. Scott (1999). Trends in Job Stability and Wages for Young Adult Men. Journal of Labor Economics 17 (October): S65-S90.

8. Booth, A and Bryan, M., 2002. Who pays for general training? New evidence for British men and women, IZA Discussion Paper 486.

9. Booth, A. and G. Zoega, 2004. Is wage compression a necessary condition for firm-financed general training? Oxford Economic Papers, Vol. 56, 88-97

10. De Grip, A. \& J. van Loo (2002). The Economics of Skills Obsolescence: A Review. Research in Labor Economics, vol. 21, JAI Press, 2002, 1-26 
11. Gritz, Mark R. (1993). The Impact of Training on the Frequency and Duration of Employment. Journal of Econometrics 57, 21-51.

12. Lillard, L. A. and Tan, H. W. (1992). Private Sector Training: Who Gets It and What Are Its Effects? Research in Labour Economics, 13, JAI Press, 1-62.

13. Loewenstein, Mark A., and James R. Spletzer. 1998. Dividing the Costs and Returns to General Training. Journal of Labor Economics 16, No. 1.

14. Lynch, Lisa M. (1991). The Role of Off-the Job vs. On-the-Job Training for the Mobility of Young Women Workers. American Economic Review 81, 151-156.

15. Topel, R.H. and M.P.Ward (1992). Job mobility and the careers of young men. Quarterly Journal of Economics, Vol. 57 No.2; 439-80

\section{NOTES}

